\title{
Clinical correlates of vitamin D deficiency in established psychosis
}

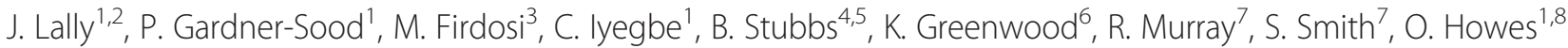 \\ and F. Gaughran ${ }^{1,2^{*}}$
}

\begin{abstract}
Background: Suboptimal vitamin D levels have been identified in populations with psychotic disorders. We sought to explore the relationship between vitamin D deficiency, clinical characteristics and cardiovascular disease risk factors among people with established psychosis.

Methods: Vitamin D levels were measured in 324 community dwelling individuals in England with established psychotic disorders, along with measures of mental health, cardiovascular risk and lifestyle choices. Vitamin D deficiency was defined as serum 25-hydroxyvitamin D (25-OHD) levels below $10 \mathrm{ng} / \mathrm{ml}$ (equivalent to $<25 \mathrm{nmol} / \mathrm{L}$ ) and "sufficient" Vitamin D as above $30 \mathrm{ng} / \mathrm{ml}(>50 \mathrm{nmol} / \mathrm{L})$.

Results: The mean 25-OHD serum level was 12.4 (SD 7.3) ng/ml, (range 4.0-51.7 ng/ml). Forty nine percent $(n=158)$ were vitamin D deficient, with only $14 \%(n=45)$ meeting criteria for sufficiency. Accounting for age, gender, ethnicity and season of sampling, serum 25-OHD levels were negatively correlated with waist circumference $(r=-0.220, p<$ $0.002)$, triglycerides $(r=-0.160, p=0.024)$, total cholesterol $(r=-0.144, p=0.043)$, fasting glucose $(r=-0.191, p=0.007)$, $\operatorname{HbA1c}(r=-0.183, p=0.01)$, and serum CRP levels $(r=-0.211, p=0.003)$ and were linked to the presence of metabolic syndrome.

Conclusions: This is the largest cross sectional study of serum 25-OHD levels in community dwelling individuals with established psychosis, indicating a high level of vitamin D deficiency. Lower vitamin D levels are associated with increased cardiovascular disease risk factors and in particular metabolic syndrome. Further research is needed to define appropriate protocols for vitamin D testing and supplementation in practice to see if this can improve cardiovascular disease risk.
\end{abstract}

Trial registration: ISRCTN number is ISRCTN58667926 Date of registration: 23/04/2010

Keywords: Schizophrenia, Psychosis, Vitamin D, Metabolic syndrome, Cardiovascular

\section{Background}

Vitamin D levels are sub-optimal in people with schizophrenia and other psychotic disorders $[1,2]$, being lower than matched controls even from the first episode of psychosis [3]. Lifestyle and physical health factors associated with low vitamin D, such as smoking [4], increased

\footnotetext{
* Correspondence: Fiona.p.gaughran@kcl.ac.uk

Howes $\mathrm{O}$ and Gaughran F: Both authors are joint last named authors and should be acknowledged as such

'Department of Psychosis Studies, Institute of Psychiatry, Psychology and Neuroscience (loPPN), King's College London, London SE5 8AF, UK

${ }^{2}$ National Psychosis Service, South London and Maudsley NHS Foundation

Trust, London, UK

Full list of author information is available at the end of the article
}

body mass index [5], inactivity, and social withdrawal (likely resulting in deceased sunlight exposure), are all more frequent in people with psychosis.

In the general population, research has demonstrated that individuals with heart failure, hypertension, stroke, and other cardiovascular diseases (CVD) tend to have lower vitamin $\mathrm{D}$ levels [6]. Moreover, type 2 diabetes mellitus is more prevalent among people with low vitamin D levels and those who spend less time in the sun [7]. In addition there is an inverse relationship between vitamin D levels and hypertension, obesity and waist circumference [8], all key components of metabolic syndrome (MetS). Recent research has demonstrated that people with psychosis demonstrate high levels of 
cardiovascular risk, MetS $[9,10]$ and type 2 diabetes mellitus [11] which are leading contributors to premature mortality in this population [12]. There is accumulating evidence that vitamin $\mathrm{D}$ deficiency may be associated with inflammatory cytokines [13] which could explain this relationship. However, to our knowledge, only one other study has investigated this in people with psychosis [14].

Previous studies of vitamin D deficiency in community patients with psychosis have had small sample sizes $[15,16]$ and few have examined the relationship between vitamin $\mathrm{D}$ status and clinical domains of an individual's illness $[15,17]$. In particular, no author has fully explored the relationship between vitamin D and cardiovascular disease risk in people with established psychosis, despite this relationship being observed in the general population [18]. Cardiovascular disease is the leading cause of premature mortality in this population [19], if vitamin D is related to cardiovascular disease risk in people with established psychosis, this may either be amenable to change or be a marker of change, and could assist in collaborative efforts to reduce cardiovascular disease in this population. Importantly, there have been no previous studies reporting the influence of lifestyle factors and duration of time spent outdoors on vitamin D levels in established psychosis.

\section{Aims}

We set out to determine the prevalence of vitamin D deficiency in a cohort of community patients with established psychotic illnesses and ascertain the relationship between vitamin $\mathrm{D}$ status and specific clinical features and in particular cardiovascular risk in psychosis.

\section{Methods}

\section{Study design}

This is a cross-sectional study of a random sample of people with established psychosis, recruited at baseline to the NIHR funded Improving Physical health and reducing substance use in Psychosis (IMPaCT) randomised controlled trial (RCT) [20].

\section{Setting}

The study took place within English community mental health teams (CMHTs). Potential participants were identified through their community mental health team carecoordinator. All care-coordinators in participating CMHTs were approached in random sequence and invited to participate. Patients on each participating care coordinator's caseload, meeting the inclusion criteria, were likewise approached in a random order and sequentially invited to participate.

\section{Clinical and sociodemographic variables}

Sociodemographic and clinical data were collected including gender, age, ethnicity, diagnosis and duration of illness (self-report measure). Diagnoses were based on ICD-10 diagnostic criteria and extracted from the documented diagnosis in the clinical notes at study recruitment. All data were collected at the same timepoint for each individual patient. Participants' mental health status was measured using the Positive And Negative Syndrome Scale (PANSS) [21], Global Assessment of Functioning (GAF) [22] and the Montgomery Asberg Depression Rating Scale (MADRS) [23]. The EuroQoL-5 dimension (EQ-5D) [24] was used to measure health related quality of life (HRQoL) in participants. Both EQ-5 D index scores and EQ-5 D visual analogue scale scores were recorded. Current smoking was recorded using the Nicotine Dependence Questionnaire [25] and alcohol use by the Alcohol Use Disorders Identification Test (AUDIT) [26]. The International Physical Activity Questionnaire (IPAQ) was used as a measure of physical activity [27]. The IPAQ measures the intensity of physical activity (high, moderate, low) and the duration of walking physical activities over the previous week and is a valid tool for use in this population [28].

All total scores from the scales were derived from the individual scale items. If any of the individual items were missing, then the total score was treated as missing.

\section{Vitamin D}

Levels of Vitamin D (serum 25-hydroxyvitamin D (25OHD)) were determined by chemiluminescence immunoassay (DiaSorin, S.P.A. Saluggia (Vercelli), Italy). Vitamin D deficiency was defined as 25-OHD levels below $10 \mathrm{ng} / \mathrm{ml}$ (equivalent to $<25 \mathrm{nmol} / \mathrm{L}$ ) and vitamin D insufficiency as 25-OHD levels between $10-20 \mathrm{ng} / \mathrm{ml}$ (equivalent to $25-50 \mathrm{nmol} / \mathrm{L}$ ). A serum level of greater than $20 \mathrm{ng} / \mathrm{ml}$ (equivalent to $>50 \mathrm{nmol} / \mathrm{L}$ ) is considered optimal [29].

\section{Cardiovascular risk factors}

Anthropometric measures were recorded as described in Gaughran et al., 2013 [20]. Additionally, we measured high sensitivity serum C-reactive protein (HS-CRP) levels. All bloods were fasting. A participant was classified as having a particular cardiovascular risk factor if the measure met the World Health Organisation reference standard for obesity or otherwise met the cut-off used in the diagnosis of metabolic syndrome (MetS) by the International Diabetes Federation [30]. Normal weight, overweight, and obesity therefore were defined as a BMI less than $25 \mathrm{~kg} / \mathrm{m}^{2}, 25$ to $29.9 \mathrm{~kg} / \mathrm{m}^{2}$, and $30 \mathrm{~kg} / \mathrm{m}^{2}$ or higher respectively; central obesity as a waist circumference $>94 \mathrm{~cm}$ in males and $>80 \mathrm{~cm}$ in females; hypertension as a systolic BP greater than or equal to $130 \mathrm{mmHg}$ or diastolic 
greater than or equal to $85 \mathrm{mmHg}$; dyslipidaemia as having a serum total cholesterol $>5 \mathrm{mmol} / \mathrm{L}$; or a LDL $>3 \mathrm{mmol} / \mathrm{L}$; and/or an HDL of $<1.03 \mathrm{mmol} / \mathrm{L}$ in males and $<1.29 \mathrm{mmol} / \mathrm{L}$ for females; and/or a serum triglyceride level $>1.7 \mathrm{mmol} / \mathrm{L}$; type 2 diabetes mellitus (DM) (fasting serum glucose $>7.0 \mathrm{mmol} / \mathrm{L}$ and/or a HbA1c $>6.5 \%$ ).

\section{Data analysis}

Statistical analysis was performed using the IBM Statistical Package for Social Sciences Statistics for Windows, Version 20.0 (Armonk, NY: IBM Corp). Variables were reported as percentages or means \pm standard deviation (SD) as appropriate. Data analysis was performed using correlation coefficients, $x^{2}$-tests, student-t tests and analysis of variance (ANOVA) for parametric data where appropriate.

The primary analysis established the prevalence of vitamin $\mathrm{D}$ deficiency in the population. In the secondary analysis we examined the relationships between serum 25-OHD levels and clinical details, including associations between 25-OHD levels and mental health status and with cardiometabolic risk factors, using correlations and ANOVA testing. Partial correlations between serum 25-OHD levels and variables of interest were examined using Pearson's coefficients controlling for age, gender, ethnicity and season of 25-OHD blood sampling. An ANOVA was conducted to assess for significant differences between mean levels of serum 25-OHD levels within groups. Post hoc analyses using the Tukey post hoc criterion for significance was conducted where ANOVA demonstrated significant differences between the group means. All statistical tests were two-sided and the $\alpha$ - level for statistical significance was 0.05 .

\section{Confounding factors}

The following proposed confounding factors were evaluated: gender, age, and ethnicity, smoking status; alcohol use; body mass index. We used the season of blood sampling as a proxy for sunlight irradiation, as it is a factor which will affect the duration and intensity of sunlight exposure. We defined the seasons as follows: summerJune to August; Autumn-September-November; WinterDecember to February; Spring-March-May.

Ethical approval for this study was obtained from The Joint South London and Maudsley and The Institute of Psychiatry NHS Research Ethics Committee. Ethical approval was granted on $17^{\text {th }}$ July 2009 (REC Ref no. 09/ $\mathrm{H} 080 / 41$ ). All participants provided informed written consent.

\section{Results}

Vitamin D levels were available for 324 patients $(59.6 \%$ male) with a mean age of $43.6(S D=10.1)$ years (see
Table 1). Participants lived in regions between latitude $52.8{ }^{\circ} \mathrm{N}$ and latitude $51.4{ }^{\circ} \mathrm{N}$, with 280 living in urban and 44 in rural settings.

\section{Vitamin D levels and deficiency}

The mean 25-OHD serum level was 12.4 (SD 7.3) ng/ml (range $4.0-51.7 \mathrm{ng} / \mathrm{ml}$ ). Almost half of the sample (48.8\%,n 158 ) were deficient in vitamin $\mathrm{D}$ while only $13.9 \%(n=45)$ had sufficient vitamin D.

\section{Vitamin D levels and clinical and demographic characteristics}

The associations between 25-OHD levels and demographic, and clinical features are shown in Table 1. Briefly, mean 25-OHD levels were significantly lower in those of black African/black Caribbean ethnicity than in those of white ethnicity. Serum 25-OHD levels did not differ between males (mean $12.2 \mathrm{ng} / \mathrm{ml}(S D=7.0)$ and females (mean $12.6 \mathrm{ng} / \mathrm{ml}(S D=7.8)(t=-0.511, p=$ $0.610)$ ); nor between urban (mean 12.4 (SD 7.5) ng/ml and rural settings (mean 12.5 (SD 6.0) $(p=0.907)$. There was no significant relationship between serum 25-OHD levels and duration of illness $(r=-0.015, p=0.808)$.

\section{Vitamin D levels and mental state}

Serum 25-OHD levels were not significantly associated with PANNS total scores $(r=-0.106, p=0.058)$; PANSS positive scores $(r=-062, p=0.272)$; PANSS negative scores $(r=-0.103, p=0.066)$; GAF score $(r=-062, p=$ $0.270)$; or MADRS score $(r=-087, p=0.117)$.

\section{Vitamin D levels and cardiovascular disease risk factors}

Associations between cardiovascular risk factors and serum 25-OHD levels are shown in Table 2. After adjustment for age, gender and ethnicity and season of sampling, serum 25-OHD levels were significantly negatively correlated with waist circumference ( $r=$ $-0.220, p<0.002)$, BMI $(r=-0.163, p=0.022)$, triglycerides $(r=-0.160, p=0.024)$, total cholesterol $(r=-0.144$, $p=0.043)$, fasting glucose $(r=-0.191, p=0.007)$, HbA1c $(r=-0.183, p=0.01)$, and CRP $(r=-0.211, p=0.003)$. Those with vitamin D deficiency (serum 25-OHD levels $<10 \mathrm{ng} / \mathrm{ml}$ ) had mean CRP levels of 7.8 (SD 10.4) $\mathrm{mg} / \mathrm{L}$, significantly higher than those who were not vitamin $\mathrm{D}$ deficient (serum CRP of 3.9 (SD 4.3) mg/L $(t=3.789, p<$ $0.001)$. Further serum 25-OHD levels were significantly negatively correlated with hypertension $(r=-0.180, p=$ 0.011).

The prevalence of metabolic syndrome (as defined by the International Diabetes Federation [30]) in association with increasing quartiles of serum 25-OHD was investigated. Participants within the highest quartile of vitamin D (mean serum 25-OHD level $22.8 \mathrm{ng}$ / $\mathrm{ml}(S D=6.3$; range $16.5-51.7 \mathrm{ng} / \mathrm{ml})$ had the lowest 
Table 1 Clinical/demographic characteristics and differences in mean vitamin D by season of sampling, age categories, ethnicity \& diagnoses

\begin{tabular}{|c|c|c|c|c|c|c|c|}
\hline & Total $(n=324)$ & Male $(n=193)$ & \multicolumn{5}{|l|}{ Female $(n=131)$} \\
\hline Mean age (SD) & $43.8(10.1)$ & $43.2(10.1)$ & \multicolumn{5}{|l|}{$44.7(10.2)$} \\
\hline Mean Duration of illness (SD) & $16.5(10.4)$ & $17.1(10.5)$ & \multicolumn{5}{|l|}{$15.6(10.4)$} \\
\hline \multirow[t]{2}{*}{ Mean Vitamin D levels } & $12.4(7.3)$ & $12.2(7.0)$ & $12.6(7.8)$ & & & & \\
\hline & \multicolumn{4}{|c|}{ Mean $25-\mathrm{OHD}$ levels $(\mathrm{ng} / \mathrm{ml}) \pm \mathrm{SD}$} & $\mathrm{T}$ & $d f$ & $P$ Value \\
\hline \multirow[t]{2}{*}{ Age categories } & \multicolumn{2}{|l|}{ Age $\leq 44(n=172)$} & \multicolumn{5}{|l|}{ Age $>44(n=152)$} \\
\hline & \multicolumn{2}{|l|}{$12.1 \pm 7.1$} & \multicolumn{2}{|l|}{$12.7 \pm 7.5$} & -0.724 & 322 & 0.663 \\
\hline \multirow[t]{3}{*}{ Diagnosis } & \multicolumn{2}{|c|}{$\begin{array}{l}\text { Non affective psychosis (i.e. Schizophrenia) } \\
(n=218)\end{array}$} & \multicolumn{5}{|c|}{$\begin{array}{l}\text { Affective psychosis (Schizoaffective disorder, } \\
\text { BPAD, psychotic depression) }(n=96)\end{array}$} \\
\hline & $11.5 \pm 6.7$ & & $14.3 \pm 8.1$ & & 3.099 & 312 & 0.061 \\
\hline & \multicolumn{4}{|c|}{ Mean 25-OHD levels $(\mathrm{ng} / \mathrm{ml}) \pm$ SD/Nitamin D deficiency \% } & $\mathrm{F}$ & df & $p$ Value \\
\hline \multirow[t]{2}{*}{ Season of sampling } & Autumn $(n=96) / 38 \%$ & Winter $(n=70) / 69 \%$ & Spring $(n=70) / 60 \%$ & Summer $(n=88) / 36 \%$ & 12.977 & 3 & $<0.001^{*}$ \\
\hline & $14.3 \pm 7.3^{1,2}$ & $9.4 \pm 5.9$ & $9.8 \pm 4.8^{2}$ & $14.7 \pm 8.5^{1,2}$ & & & \\
\hline \multirow[t]{2}{*}{ Ethnicity } & Black $(n=104)$ & White $(n=183)$ & Asian $(n=12)$ & Mixed/Others $(n=24)$ & 2.707 & 3 & $0.008^{*}$ \\
\hline & $10.6 \pm 5.9^{3}$ & $13.5 \pm 8.1^{3}$ & $10.7 \pm 8.4$ & $12.4 \pm 4.9$ & & & \\
\hline
\end{tabular}

Student-t tests and analysis of variance (ANOVA) were conducted to assess for differences in serum 25 -OHD between groups. The *values represent the significant difference with $p<0.05$

$1,2$ Mean serum 25-hydroxyvitamin D (25-OHD) levels were significantly decreased in those who had blood sampling in Winter compared to Summer or Autumn ( $p<0.001)$ and were significantly decreased in Spring

${ }^{3}$ Mean 25-OHD levels were significantly decreased in those of black ethnicity compared to those of white ethnicity $(p=0.002)$ 
Table 2 Significant bivariate and partial correlations between serum levels of 25-Hydroxyvitamin D (25-OHD) and cardiometabolic risk factors among patients with psychosis

\begin{tabular}{lll}
\hline & $\begin{array}{l}\text { Bivariate } r \text { for } \\
\text { 25-OHD level }\end{array}$ & $\begin{array}{c}\text { Partial } r \text { for } \\
\text { 25-OHD level }\end{array}$ \\
\hline Waist & $-0.188^{* *}$ & $-0.220^{* *}$ \\
BMI & $-0.149^{*}$ & $-0.163^{*}$ \\
Type 2 DM & $-0.147^{*}$ & -0.128 \\
MetS & $-0.117^{*}$ & $-0.151^{*}$ \\
Fasting glucose & $-0.135^{*}$ & $-0.191^{* *}$ \\
HbA1c & $-0.146^{* *}$ & $-0.183^{* *}$ \\
Serum triglyceride & $-0.133^{*}$ & $-0.160^{*}$ \\
Serum total cholesterol & $-0.128^{*}$ & $-0.144^{*}$ \\
Systolic blood pressure & -0.084 & -0.134 \\
Diastolic blood pressure & $-0.151^{* *}$ & -0.128 \\
CRP level & $-0.206^{* *}$ & $-0.211^{* *}$ \\
\hline
\end{tabular}

Bivariate and partial correlations ( $r$ ) between serum 25-OHD levels and cardiometabolic risk factors were examined using Pearson's coefficients, with controlling for age, gender, ethnicity and season of 25-OHD blood sampling. The ${ }^{*}$ values represent the significant difference with $p<0.05$, ${ }^{* *}$ with $p<0.01$ and ${ }^{* * *}$ with $p<0.001$

prevalence of MetS ( $N=73,20.5 \%)$ (see Fig. 1). Participants within the first $(N=92,39.1 \%$ MetS $)$, second $(N=93,48.3 \%$ MetS) and third $(N=95,43.15 \%$ MetS) lowest vitamin D quartiles were at 2.48 (OR $95 \%$ CI 1.22 to 5.03), 3.62 (OR $95 \%$ CI 1.80 to 7.28), 2.93 (OR $95 \%$ CI 1.46 to 5.89 ) greater odds of having MetS compared to participants within the highest quartile of vitamin D.

\section{Vitamin D levels and lifestyle factors}

There was no significant difference between serum 25-OHD levels in current tobacco smokers $(n=197)$ versus non-smokers $(n=127)(p=0.821)$ nor any association between serum 25-OHD levels and alcohol use as measured by the AUDIT $(p=0.455)$. The use of vitamin supplements $(n=20)$ did not affect 25 OHD levels $(t=-0.712, p=0.477)$.

Those engaging in low intensity physical activity over the week prior to sampling $(n=137)$ had significantly lower 25-OHD levels (mean $=10.91 \mathrm{ng} / \mathrm{ml}(S D=6.87)$ than those who engaged in moderate or high intensity physical activity $(n=187)($ mea $n=13.45 \mathrm{ng} / \mathrm{ml} \quad(S D=$ 7.47) $(t=-3.123, d f=322, p=0.002)$. There was a direct relationship between serum 25-OHD levels and the amount of hours spent outdoors $(r=0.140, p=0.012)$.

\section{Discussion}

To our knowledge, this is the largest study to date investigating 25-OHD levels in community dwelling individuals with established psychosis. Nearly half of our study sample had vitamin D deficiency, more than in previously published studies of psychosis, for example the $26 \%(n=34)$ seen in a Norwegian study of outpatients with psychosis [15]. As in the general population, black

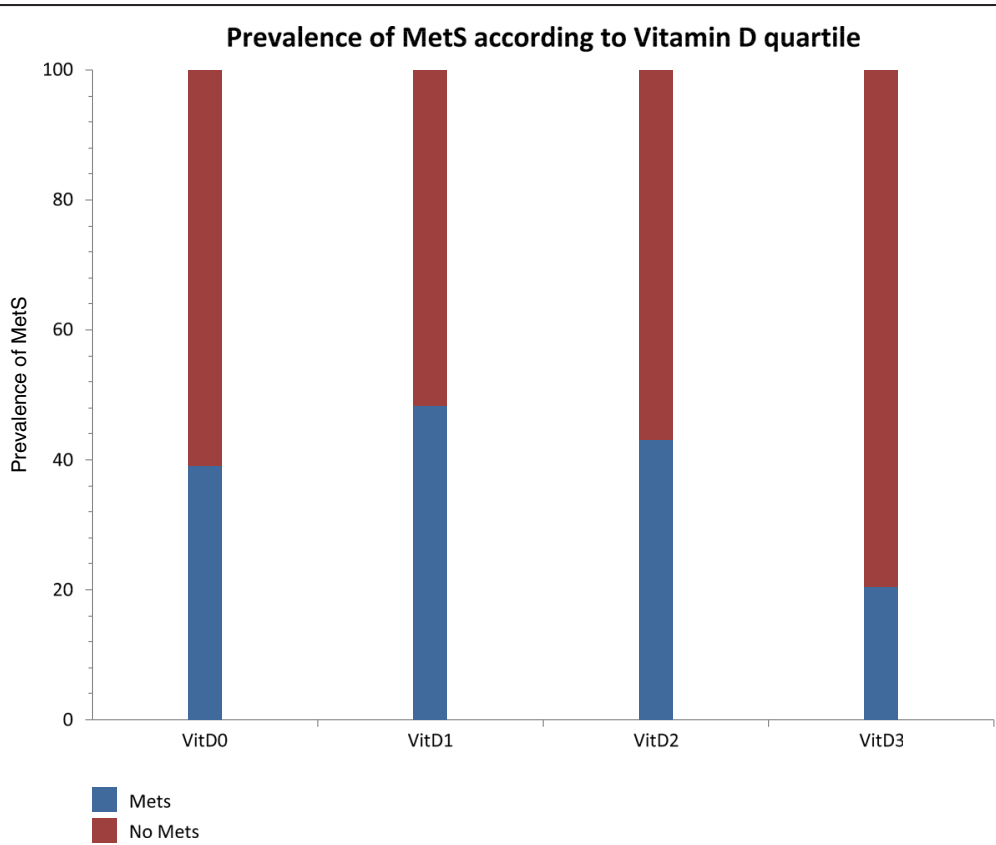

Fig. 1 Prevalence of Metabolic Syndrome (MetS) according to Vitamin D quartile. footnote: First (VitDO), second (VitD1), third (VitD2) and fourth (VitD3) quartiles with mean serum 25-OHD levels of $5.4 \mathrm{ng} / \mathrm{ml}(S D=1.0), 8.6 \mathrm{ng} / \mathrm{ml}(S D=0.94), 12.8 \mathrm{ng} / \mathrm{ml}(S D=1.8)$, and $22.8 \mathrm{ng} / \mathrm{ml}(S D=6.3)$, and 25-OHD levels in each of VitDO, VitD1, VitD2 and VitD3 which ranged from 34.0-7.0 ng/ml, 7.0-10.2 ng/ml, 10.3-16.4 ng/ml and $16.5-51.7 \mathrm{ng} /$ $\mathrm{ml}$. Logistic regression was performed to test the differences 
African or black Caribbean people with psychosis had lower levels than their white counterparts. Moreover, we have for the first time in a population with established psychosis, identified that those with the highest levels of vitamin D have a lower prevalence of MetS (20.5\%), compared to those in the lowest (39.1\%), second $(48.3 \%)$ and third quartile (43.1 \%) of vitamin D (all $p<$ $0.01)$. For the first time we have demonstrated that those people with psychosis that engage in more moderate and vigorous physical activity have significantly higher levels of vitamin $\mathrm{D}(p=0.002)$.

\section{Vitamin D and cardiometabolic risk}

Perhaps the most novel and significant finding within this study is the relationships we observed between 25OHD levels and cardiovascular risk factors in psychotic illnesses. We observed a clear inverse relationship between rising vitamin D levels and decreased MetS risk, which has important implications given that MetS and cardiovascular disease are highly prevalent $[9,10]$ and leading causes of premature mortality [19]. Of interest, we identified associations with hypertension and low 25$\mathrm{OH}$ levels. This is likely to be clinically important as in the general population low 25-OHD levels are associated with the risk of incident CVD and specifically hypertension [31]. Further, the inverse relationship between 25OHD levels and dyslipidaemia, previously demonstrated in large general population samples, and replicated here, is worthy of further exploration given the high risk of cardiovascular morbidity in psychosis. The strongest correlations with low 25-OHD levels were with factors related to high body fat. This is consistent with findings that those with increased adipose tissue stores (in which vitamin $\mathrm{D}$, being fat soluble, is stored), due to obesity, have lower circulating vitamin $\mathrm{D}$ due to this increased storage capacity [32]. The low 25-OHD levels could then be a secondary manifestation of obesity.

Given these results, the questions that one could pose is, would the supplementation of vitamin D in psychosis prevent and/or ameliorate cardiovascular and metabolic risk? This is a key question that needs addressing in future work.

Raised levels of the inflammatory marker CRP, which is pathogenic in the development of CVD, have been described in both schizophrenia [33] and bipolar affective disorder [34]. This is the largest study to identify an association between raised CRP and vitamin D deficiency in established psychosis, with a similar inverse relationship between CRP and serum 25-OHD having been previously identified in schizophrenia patients in a casecontrol study [14]. This is interesting in the context of vitamin D's known anti-inflammatory properties, especially given the recent resurgence of research into autoimmunity and inflammation in psychosis. Clinical trials have shown inconsistent results regarding the benefits of vitamin D supplementation in reducing CRP levels in the general population [35], but this may be worth further examination in psychosis.

Another novel finding from this study is the association between low vitamin $\mathrm{D}$ in established psychotic disorders and decreased physical activity [15]. This further adds to the notion that engaging people with psychosis may improve health outcomes, including vitamin $\mathrm{D}$ status. The association between time spent outside and higher serum 25-OHD levels provides support for selective strategies to encourage increased outdoor activity in people with psychosis - not only to boost vitamin D levels but for all the other known health benefits. Vitamin D levels were not appreciably higher in those taking vitamin D supplements. This may support the notion that most of these supplements contain much too low a dose of vitamin D to have a meaningful effect on serum levels [36], although there remains the possibility, not tested, that supplements may have been prescribed because of an already suspected inadequate level or that treatment non-adherence may have occurred.

The lack of a prospective study design means further work is needed to answer the question of causality; however, in the meantime it is important that primary and secondary health care professionals are aware of the high rates of vitamin D deficiency in people with established psychosis. This is particularly so, given that people with psychotic illnesses residing in the geographical area where this work was carried out, have a life span shortened by up to 18 years [37]. This reduced life expectancy is largely due to cardiovascular disease, for which vitamin D deficiency is a known risk factor in the general population $[31,18]$. It is also clinically noteworthy that vitamin D deficiency may exacerbate the effects of lower bone mineral density and increased osteoporosis seen in psychosis [38, 39], particularly as osteoporosis is more prevalent in black patients [40]. This may partially account for the fact that people with schizophrenia have more fractures than the general population [41].

\section{Comparison with other populations}

Studies of inpatients with schizophrenia have reported vitamin $\mathrm{D}$ deficiency rates of $11 \%-26 \%$ [1, 2]. A mean 25-OHD level of $29.0 \mathrm{ng} / \mathrm{ml}$ was observed in one inpatient sample of 34 schizophrenia patients, much higher than that in our UK sample [42]. Our vitamin D deficiency prevalence of $50 \%$ contrasts with that of an epidemiological cohort $(N=7437)$ of UK males, where $16 \%$ had vitamin D deficiency (using the same definitions) in the winter and spring (64\% in our study), falling to $3 \%$ in the summer and autumn (36\% in our study) [43]. In the 2004 UK National Health Survey, $14 \%$ of men and $15 \%$ of women were vitamin D 
deficient (using the same definitions) compared to of $48 \%$ of males and $51 \%$ of females in our study. This excess is highlighted when an aged-matched comparison is used; for those aged 35-49 in the same study, the mean 25-OHD level was $48 \mathrm{nmol} / \mathrm{L}$ (equivalent to $19.2 \mathrm{ng} / \mathrm{ml}$ ), compared to the mean 25-OHD level of $12.1 \mathrm{ng} / \mathrm{ml}$ in this age group in our study [44].

Similar to findings from a recent mini meta-analysis, [45] we also observed that individuals with schizophrenia had a trend towards lower 25-OHD levels than those with other psychotic disorders. However, since our numbers with diagnoses of schizoaffective disorder and bipolar affective disorder are relatively small, it is difficult to draw firm conclusions. We did not identify significant correlations with clinical symptoms and 25-OHD levels, but an inverse relationship between 25-OHD levels and psychotic and depressive symptoms is the overall trend in these analyses in keeping with expectations.

\section{Strengths and limitations}

The study is limited by its cross sectional design, meaning that no inference on the directionality of the association between vitamin $\mathrm{D}$ and psychotic disorders or symptoms can be made. As such further replication in large prospective cohorts would be valuable. We have identified a higher prevalence of vitamin D deficiency in established psychosis when compared to general population samples, though comparisons are limited by an inability to control for ethnicity and by the use of different assay techniques. The use of automated immunoassays to quantify $25-\mathrm{OHD}$ levels may limit the generalisability of the findings due to variable concordance between different mechanisms of 25-OHD measurement. In particular, immunoassays may underestimate true vitamin $\mathrm{D}$ deficiency, as they can overestimate serum 25-OHD results at serum levels $<8 \mathrm{ng} / \mathrm{ml}(<20 \mathrm{nmol} / \mathrm{L})$ [46], which could have potentially led to an underestimate of vitamin D deficiency in this sample. Study strengths include the large sample size, random sampling across multiple sites, clinical diagnoses of schizophrenia and other psychotic disorders, measures of clinical status and the multi-ethnicity of the population, which should enhance the study's generalisability.

\section{Conclusions}

Because of the potential adverse effects of vitamin D deficiency on the skeletal system and on cardiovascular morbidity, the question of whether to recommend widespread screening for vitamin D deficiency or routine vitamin D supplementation arises. There is as yet no evidence that Vitamin D supplementation will improve psychotic symptoms, so the question should be looked at in the light of general population guidelines. Evidence is lacking here too, pending the results of large ongoing
RCTs [47] and clinical equipoise remains about the general health benefits of routine population screening and supplementation of vitamin D [48]. However, given the extremely low levels of vitamin $\mathrm{D}$ seen in this vulnerable population, large randomised trials, specifically in psychosis, are urgently needed to determine whether supplementation with vitamin $\mathrm{D}$ is an effective means of ameliorating mental health outcomes [49], boosting cardiometabolic health and ultimately reducing mortality in psychosis.

\section{Ethics approval and consent to participate}

Ethical approval for this study was obtained from The Joint South London and Maudsley and The Institute of Psychiatry NHS Research Ethics Committee. Ethical approval was granted on 17th July 2009 (REC Ref no. 09/H080/41). All participants provided informed written consent.

\section{Availability of data and materials}

The data cannot be shared due to confidentiality issues, though individual data requests can be considered.

\section{Abbreviations}

25-OHD: 25-hydroxyvitamin D; ANOVA: analysis of variance; AUDIT: alcohol use disorders identification test; $\mathrm{CMHTs}$ : community mental health teams; CVD: cardiovascular diseases; DM: diabetes mellitus; EQ-5D: EuroQoL-5 dimension; GAF: global assessment of functioning; HS-CRP: high sensitivity serum C-reactive protein; IPAQ: international physical activity questionnaire; MADRS: montgomery asberg depression rating scale; MetS: metabolic syndrome; PANSS: positive and negative syndrome scale; RCT: randomised controlled trial.

\section{Competing interests}

RMM has received payment for lectures including service on speakers' bureaus for BMS, Janssen, AZ.

Dr Howes has received investigator-initiated research funding from and/or participated in advisory/ speaker meetings organised by Astra-Zeneca, Autifony, BMS, Eli Lilly, Heptares, Jansenn, Lundbeck, Lyden-Delta, Otsuka, Servier, Sunovion, Rand and Roche. Neither Dr Howes or his family have been employed by or have holdings/ a financial stake in any biomedical company. FG has received honoraria for advisory work and lectures from Roche, BMS, Lundbeck, Otsuka and Sunovion and has a family member with professional links to Lilly and GSK;

The other authors, JL, PGS, MF, Cl, BS, KG and SS have no conflict of interest to declare.

We affirm that the manuscript is an honest, accurate, and transparent account of the study being reported; that no important aspects of the study have been omitted; and that any discrepancies from the study as planned (and, if relevant, registered) have been explained.

\section{Authors' contributions}

All authors (JL, PGS, MF, Cl, BS, KG, RMM, SS, OH and FG) made substantial contributions to the conception and design of the work. JL, PGS, MF, SS, OH and FG were involved in the acquisition and analysis of the data, and $J$, $\mathrm{PGS}, \mathrm{MF}, \mathrm{Cl}, \mathrm{BS}, \mathrm{KG}, \mathrm{RMM}, \mathrm{SS}, \mathrm{OH}$ and $\mathrm{FG}$ in the interpretation of data for the work; $J$ and FG created the first draft of the work and all, JL, PGS, MF, Cl, BS, $\mathrm{KG}, \mathrm{RMM}, \mathrm{SS}, \mathrm{OH}$ and $\mathrm{FG}$ were involved in the revision and completion of the work; All authors gave final approval of the version to be submitted and published and are in agreement to be accountable for all aspects of the work in ensuring that questions related to the accuracy or integrity of any part of the work are appropriately investigated and resolved. 


\section{Acknowledgements}

This paper summarises independent research funded by the National Institute for Health Research (NIHR) under its IMPACT Programme (Grant Reference Number RP-PG-0606-1049).This study was also partially funded by Medical Research Council-UK (no. MC-A656-5QD30), Maudsley Charity (no. 666), Brain and Behavior Research Foundation, and Wellcome Trust (no. 094849/Z/10/Z) grants to Dr Howes and the National Institute for Health Research (NIHR) Biomedical Research Centre at South London and Maudsley NHS Foundation Trust and King's College London. The views expressed are those of the author (s) and not necessarily those of the National Health Service (NHS), the NIHR or the Department of Health

We thank all the participants in this study for generously helping us in this research.

\section{Author details}

'Department of Psychosis Studies, Institute of Psychiatry, Psychology and Neuroscience (loPPN), King's College London, London SE5 8AF, UK. ${ }^{2}$ National Psychosis Service, South London and Maudsley NHS Foundation Trust, London, UK. ${ }^{3}$ South London and Maudsley NHS Foundation Trust, London, UK. ${ }^{4}$ Health Service and Population Research Department, Institute of Psychiatry, Psychology and Neuroscience, King's College London, London, UK. ${ }^{5}$ Physiotherapy Department, South London and Maudsley NHS Foundation Trust, London, UK. ${ }^{6}$ Honorary Senior Research Fellow, School of Psychology, University of Sussex, Brighton and Early Intervention in Psychosis Service, Sussex Partnership NHS Foundation Trust, West Sussex, UK. ${ }^{7}$ Institute of Psychiatry, Psychology and Neuroscience (IoPPN), King's College London and Honorary Consultant, National Psychosis Service, South London and Maudsley NHS Foundation Trust, London, UK. ${ }^{8}$ Department of Psychosis Studies, MRC Clinical Sciences Centre, Imperial College- Hammersmith Hospital Campus, London, W12 ONN, UK, London, UK.

\section{Received: 1 September 2015 Accepted: 11 March 2016} Published online: 22 March 2016

\section{References}

1. Berk M, Jacka FN, Williams $L$, Ng F, Dodd S, Pasco JA. Is this D vitamin to worry about? Vitamin D insufficiency in an inpatient sample. Aust N Z J Psychiatry. 2008;42(10):874-8.

2. Menkes DB, Lancaster K, Grant M, Marsh RW, Dean P, du Toit SA. Vitamin D status of psychiatric inpatients in New Zealand's Waikato region. BMC Psychiatry. 2012;12:68.

3. Crews M, Lally J, Gardner-Sood P, Howes O, Bonaccorso S, Smith S, Murray RM, Di Forti M, Gaughran F. Vitamin D deficiency in first episode psychosis: A case-control study. Schizophr Res. 2013;150(2-3):533-7.

4. Cutillas-Marco E, Fuertes-Prosper A, Grant WB, Morales-Suarez-Varela M. Vitamin D deficiency in South Europe: effect of smoking and aging. Photodermatol Photoimmunol Photomed. 2012;28(3):159-61.

5. Vimaleswaran KS, Berry DJ, Lu C, Tikkanen E, Pilz S, Hiraki LT, Cooper JD, Dastani Z, Li R, Houston DK, et al. Causal relationship between obesity and vitamin D status: bi-directional Mendelian randomization analysis of multiple cohorts. PLoS Med. 2013;10(2):1-13.

6. Liu L, Chen M, Hankins SR, Nunez AE, Watson RA, Weinstock PJ, Newschaffer CJ, Eisen HJ. Serum 25-hydroxyvitamin D concentration and mortality from heart failure and cardiovascular disease, and premature mortality from allcause in United States adults. Am J Cardiol. 2012;110(6):834-9.

7. Lindqvist PG, Olsson $\mathrm{H}$, Landin-Olsson M. Are active sun exposure habits related to lowering risk of type 2 diabetes mellitus in women, a prospective cohort study? Diabetes Res Clin Pract. 2010;90(1):109-14.

8. Lindqvist PG. Cardiology Patient Page. On the possible link between vitamin D deficiency and cardiovascular disease: should we D-lighten our lives? Circulation. 2014;129(13):e413-4.

9. Stubbs B, Vancampfort D, De Hert M, Mitchell AJ. The prevalence and predictors of type two diabetes mellitus in people with schizophrenia: a systematic review and comparative meta-analysis. Acta Psychiatr Scand. 2015;132(2):144-57. n/a-n/a.

10. Vancampfort D, Stubbs B, Mitchell AJ, De Hert M, Wampers M, Ward PB, Rosenbaum S, Correll CU. : Risk of metabolic syndrome and its components in people with schizophrenia and related psychotic disorders, bipolar disorder and major depressive disorder: a systematic review and metaanalysis. World Psychiatry 2015 (in press).
11. Gardner-Sood P, Lally J, Smith S, Atakan Z, Ismail K, Greenwood KE, Keen A, O'Brien C, Onagbesan O, Fung C, et al. Cardiovascular risk factors and metabolic syndrome in people with established psychotic illnesses: baseline data from the IMPaCT randomized controlled trial. Psychol Med. 2015;45(12):1-11.

12. Lawrence D, Hancock KJ, Kisely S. The gap in life expectancy from preventable physical illness in psychiatric patients in Western Australia: retrospective analysis of population based registers. BMJ. 2013;346:f2539.

13. Tiwari S, Pratyush DD, Gupta SK, Singh SK. Vitamin D deficiency is associated with inflammatory cytokine concentrations in patients with diabetic foot infection. Br J Nutr. 2014;112(12):1938-43.

14. Zhu DM, Liu Y, Zhang AG, Chu ZX, Wu Q, Li H, Ge JF, Dong Y, Zhu P. High levels of vitamin $D$ in relation to reduced risk of schizophrenia with elevated C-reactive protein. Psychiatry Res. 2015;228(3):565-70.

15. Berg AO, Melle I, Torjesen PA, Lien L, Hauff E, Andreassen OA. A crosssectional study of vitamin $D$ deficiency among immigrants and Norwegians with psychosis compared to the general population. J Clin Psychiatry. 2010;71(12):1598-604.

16. Humble MB, Gustafsson S, Bejerot S. Low serum levels of 25-hydroxyvitamin D (25-OHD) among psychiatric out-patients in Sweden: relations with season, age, ethnic origin and psychiatric diagnosis. J Steroid Biochem Mol Biol. 2010;121(1-2):467-70.

17. Itzhaky D, Amital D, Gorden K, Bogomolni A, Arnson Y, Amital H. Low serum Vitamin D concentrations in patients with schizophrenia. Isr Med Assoc J. 2012;14(2):88-92.

18. Chowdhury R, Kunutsor S, Vitezova A, Oliver-Williams C, Chowdhury S, Kiefte-de-Jong JC, Khan H, Baena CP, Prabhakaran D, Hoshen MB, et al. Vitamin D and risk of cause specific death: systematic review and metaanalysis of observational cohort and randomised intervention studies. BMJ. 2014;348:g1903.

19. Walker E, McGee RE, Druss BG. Mortality in mental disorders and global disease burden implications: A systematic review and meta-analysis. JAMA Psychiatry. 2015;72(4):334-41.

20. Gaughran F, Stahl D, Ismail K, Atakan Z, Lally J, Gardner-Sood P, Patel A, David A, Hopkins D, Harries B, et al. Improving physical health and reducing substance use in psychosis - randomised control trial (IMPACT RCT): study protocol for a cluster randomised controlled trial. BMC Psychiatry. 2013;13(1):263.

21. Kay SR, Opler LA, Lindenmayer JP. The Positive and Negative Syndrome Scale (PANSS): rationale and standardisation. Br J Psychiatry Suppl. 1989;7:59-67.

22. American Psychiatric Association. Multiaxial assessment. In: Diagnostic and Statistical Manual of Mental Disorders (4th edn, text revised) (DSM-IV-TR). USA: APA; 2002

23. Montgomery SA, Asberg M. A new depression scale designed to be sensitive to change. Br J Psychiatry. 1979;134:382-9.

24. EuroQol Group. EuroQol-a new facility for the measurement of health-related quality of life. Health Policy (Amsterdam, Netherlands). 1990;16(3):199-208.

25. Fagerstrom KO, Schneider NG. Measuring nicotine dependence: a review of the Fagerstrom Tolerance Questionnaire. J Behav Med. 1989;12(2):159-82.

26. Saunders JB, Aasland OG, Babor TF, DeLaFuente JR, Grant M. Development of the Alcohol Use Disorders Identification Test (AUDIT): WHO collaborative project on early detection of persons with harmful alcohol consumption II. Addiction. 1993;88:617-29.

27. Craig CL, Marshall AL, Sjostrom M, Bauman AE, Booth ML, Ainsworth BE, Pratt $M$, Ekelund $U$, Yngve A, Sallis JF, et al. International physical activity questionnaire: 12-country reliability and validity. Med Sci Sports Exerc. 2003;35(8):1381-95.

28. Soundy A, Roskell C, Stubbs B, Vancampfort D. Selection, use and psychometric properties of physical activity measures to assess individuals with severe mental illness: a narrative synthesis. Arch Psychiatr Nurs. 2014;28(2):135-51.

29. Pearce SH, Cheetham TD. Diagnosis and management of vitamin D deficiency. BMJ. 2010;11(340):142-7.

30. Alberti KG, Zimmet $P$, Shaw J. The metabolic syndrome-a new worldwide definition. Lancet. 2005;366(9491):1059-62.

31. Wang TJ, Pencina MJ, Booth SL, Jacques PF, Ingelsson E, Lanier K, Benjamin EJ, D'Agostino RB, Wolf M, Vasan RS. Vitamin D deficiency and risk of cardiovascular disease. Circulation. 2008;117(4):503-11.

32. Wortsman J, Matsuoka LY, Chen TC, Lu Z, Holick MF. Decreased bioavailability of vitamin D in obesity. Am J Clin Nutr. 2000;72(3):690-3.

33. Suvisaari J, Loo BM, Saarni SE, Haukka J, Perala J, Saarni SI, Viertio S, Partti K, Lonnqvist J, Jula A. Inflammation in psychotic disorders: a population-based study. Psychiatry Res. 2011;189(2):305-11. 
34. De Berardis D, Conti CM, Campanella D, Carano A, Scali M, Valchera A, Serroni N, Pizzorno AM, D'Albenzio A, Fulcheri M, et al. Evaluation of Creactive protein and total serum cholesterol in adult patients with bipolar disorder. Int J Immunopathol Pharmacol. 2008;21(2):319-24.

35. Fry CM, Sanders TA. Vitamin D and risk of CVD: a review of the evidence. Proc Nutr Soc. 2015;74:1-13.

36. LeBlanc ES, Perrin N, Johnson JD, Ballatore A, Hillier T. Over-the-counter and compounded vitamin d: Is potency what we expect? JAMA Internal Medicine. 2013;173(7):585-6.

37. Chang C-K, Hayes RD, Perera G, Broadbent MTM, Fernandes AC, Lee WE, Hotopf M, Stewart R. Life Expectancy at Birth for People with Serious Mental IIIness and Other Major Disorders from a Secondary Mental Health Care Case Register in London. PLoS One. 2011;6(5):1-6.

38. Stubbs B, De Hert M, Sepehry AA, Correll CU, Mitchell AJ, Soundy A, Detraux $J$, Vancampfort D. A meta-analysis of prevalence estimates and moderators of low bone mass in people with schizophrenia. Acta Psychiatr Scand. 2014; 130(6):470-86.

39. Meaney AM, Smith S, Howes OD, O'brien M, Murray RM, O'keane V. Effects of long-term prolactin-raising antipsychotic medication on bone mineral density in patients with schizophrenia. Br J Psychiatry. 2004;184(6):503-8.

40. Howes OD, Wheeler MJ, Meaney AM, O'Keane V, Fogelman I, Blake G, Murray RM, Smith S. Bone mineral density and its relationship to prolactin levels in patients taking antipsychotic treatment. J Clin Psychopharmacol. 2005:25(3):259-61.

41. Stubbs B, Gaughran F, Mitchell AJ, De Hert M, Farmer R, Soundy A, Rosenbaum S, Vancampfort D. Schizophrenia and the risk of fractures: a systematic review and comparative meta-analysis. Gen Hosp Psychiatry. 2015;37(2):126-33.

42. Schneider B, Weber B, Frensch A, Stein J, Fritz J. Vitamin D in schizophrenia, major depression and alcoholism. J Neural Transm. 2000;107(7):839-42.

43. Hypponen E, Power C. Hypovitaminosis D in British adults at age $45 \mathrm{y}$ : nationwide cohort study of dietary and lifestyle predictors. Am J Clin Nutr. 2007;85(3):860-8

44. Ruston DHJ, Henderson L, Gregory J. Vol 4. : The National Diet and Nutrition Survey: adults aged 19 to 64 years. Nutritional status (anthropometry and blood analytes), blood pressure and physical activity. In: Office for National Statistics, editor. The Stationery Office. London, United Kingdom: Office for National Statistics; 2004.

45. Belvederi Murri $M$, Respino $M$, Masotti M, Innamorati M, Mondelli V, Pariante C, Amore M. Vitamin D and psychosis: mini meta-analysis. Schizophr Res. 2013;150(1):235-9.

46. Farrell C-JL, Martin S, McWhinney B, Straub I, Williams P, Herrmann M. Stateof-the-Art Vitamin D Assays: A Comparison of Automated Immunoassays with Liquid Chromatography-Tandem Mass Spectrometry Methods. Clin Chem. 2012;58(3):531-42.

47. Manson JE, Bassuk SS. Vitamin D research and clinical practice: at a crossroads. JAMA. 2015;313(13):1311-2.

48. Ross AC, Manson JE, Abrams SA, Aloia JF, Brannon PM, Clinton SK, DurazoArvizu RA, Gallagher JC, Gallo RL, Jones G, et al. The 2011 report on dietary reference intakes for calcium and vitamin D from the Institute of Medicine: what clinicians need to know. J Clin Endocrinol Metab. 2011;96(1):53-8.

49. McGrath J. Is it time to trial vitamin D supplements for the prevention of schizophrenia? Acta Psychiatr Scand. 2010;121:321-4.

\section{Submit your next manuscript to BioMed Central and we will help you at every step:}

- We accept pre-submission inquiries

- Our selector tool helps you to find the most relevant journal

- We provide round the clock customer support

- Convenient online submission

- Thorough peer review

- Inclusion in PubMed and all major indexing services

- Maximum visibility for your research

Submit your manuscript at www.biomedcentral.com/submit
) Biomed Central 